\title{
The Precipitation of Carbides during Tempering of High Carbon Martensite*
}

\author{
By Y.Ohmori** and S. Sugisawa**
}

\begin{abstract}
The tempering process of high carbon martensite was investigated by means of the electrical resistivity measurement, dilatometry, and transmission electron microscopy. The first stage of tempering is not the precipitation of $\varepsilon$-carbide, but is probably the pre-precipitation stage such as the segregation of carbon atoms to the lattice defects or the carbon cluster formation. The second stage is the precipitation of $\varepsilon$-carbide which is related to the martensite by Jack's orientation relationship. The retained austenite decomposed into lower bainite in the temperature range between $230^{\circ}$ and $330^{\circ} \mathrm{C}$. Tempering up to $330^{\circ} \mathrm{C}$ produced $\chi$-carbide on the twin interfaces and this exhibited the monoclinic $\operatorname{Pd}_{5} \mathrm{~B}_{2}$ type structure determined by Duggin. Further tempering up to $400^{\circ} \mathrm{C}$, the in-situ transformation of $\chi$-carbide into cementite occurred.
\end{abstract}

(Received November 9, 1970)

\section{Introduction}

When high carbon martensite is heated slowly, it is considered that it decomposes in three distinct stages, namely the precipitation of $\varepsilon$-carbide with reducing the tetragonality, the decomposition of retained austenite, and the formation of cementite from $\varepsilon$-carbide.

$\varepsilon$-carbide which formed during the first stage of tempering was discovered by Jack ${ }^{(1)}$ using X-ray technique and he suggested the following $\varepsilon$-carbide/martensite orientation relationship :

$$
\begin{aligned}
& (011)_{m} / /(\overline{1} 101)_{\varepsilon}, \\
& (101)_{m} / /(0001)_{\varepsilon} .
\end{aligned}
$$

By means of transmission electron microscopy, such a precipitation of $\varepsilon$-carbide was first observed by Wells ${ }^{(2)}$ in an $0.5 \% \mathrm{C}-23.8 \% \mathrm{Ni}-\mathrm{Fe}$ alloy martensite tempered at $200^{\circ} \mathrm{C}$ and later by Tekin and Kelly ${ }^{(3)}$. Recently Murphy and Whiteman ${ }^{(4)}$ showed that the growth direction of $\varepsilon$-carbide coincided with the minimum misfit direction, $[01 \overline{1} 0]_{\varepsilon} \|\langle 211\rangle_{m}$. Nagakura et al. ${ }^{(5)(6)}$ investigated synthetic iron carbides using an electron diffraction technique and confirmed that the $\varepsilon$-carbide has an $\varepsilon-\mathrm{Fe}_{3} \mathrm{~N}$ type structure. However, Hirotsu et al. ${ }^{(7)}$ examined the tempering stage of a high carbon martensite and found that the $\varepsilon$-carbide did not exhibit the exact 6-fold symmetry about the direction normal to the basal plane. Defining the $\varepsilon$-carbide to be an orthorhombic structure of the $\mathrm{Co}_{2} \mathrm{~N}$ type with $a=4.70, b=$ 4.32 , and $c=2.83 \AA$, they called it $\eta$-carbide.

The second stage of tempering is thought to be the

* This paper was presented at the Autumn Meeting of the Japan Institute of Metals in October, 1970.

** Central Research Laboratories, Sumitomo Metal Industries, Ltd., Amagasaki, Japan.

(1) K. H. Jack : J. Iron Steel Inst., 169 (1951), 26.

(2) M. G. H. Wells : Acta Met., 12 (1964), 389.

(3) E. Tekin and P.M. Kelly : Precipitation from Iron-base Alloys, Gordon and Breach Science Publishers, London, (1965).

(4) S. Murphy and J. A. Whiteman : Met. Trans., I (1970), 843.

(5) S. Nagakura : J. Phys. Soc. Japan, 14 (1959), 186.

(6) S. Oketani and S. Nagakura : J. Phys. Soc. Japan, 17 (1962), Suppl. B-II, 235. decomposition of retained austenite into the lower bainite containing $\varepsilon$-carbide in the temperature range between $230^{\circ}$ and $280^{\circ} \mathrm{C}$. Oketani et al. ${ }^{(8)}$ demonstrated this decomposition to occur at $270^{\circ} \mathrm{C}$ in a eutectoid steel using a differencial thermal analysis, whereas Ino et al. ${ }^{(9)}$ concluded its occurrence at $220^{\circ} \mathrm{C}$ from Moessbauer spectrum measurements.

The last stage of tempering is achieved in the temperature range between $260^{\circ}$ and $360^{\circ} \mathrm{C}$. Jack showed that thin platelets of cementite formed at the beginning of this stage ${ }^{(10)}$. In high carbon steels, the transformation twin interfaces are potent nucleation sites for the cementite formation and the cementite is related to the ferrite by Bagaryatskii's orientation relationship ${ }^{(2)(3)(11)}$.

Although there is no direct evidence of its existence in steels, Nagakura et al. ${ }^{(5)(6)}$, Duggin et al. ${ }^{(12)(18)}$, and Jack and Wild ${ }^{(14)}$ have shown that $\chi$-carbide can be produced synthetically in the temperature range between $\varepsilon$-carbide and cementite formations. Duggin et al. (12)(13) examined its crystal structure by means of an $\mathrm{X}$-ray technique and showed that it has a monoclinic $\mathrm{Pd}_{5} \mathrm{~B}_{2}$ type structure with $a=11.562, b=4.573, c=$ $5.060 \AA$, and $\beta=97.74^{\circ}$. The formation of $\chi$-carbide in tempered martensite has also been suggested by Crangle and Sucksmith ${ }^{(15)}$ from the results of magnetic measurements, although this has hitherto not been confirmed by means of transmission electron microscopy.

The aim of the present study is to clarify the mutual relationship between these phenomena during the process of tempering of high carbon martensite.

(7) Y. Hirotsu, S. Nagakura and S. Oketani : Proc. Int. Con. Sci. Tech. Iron and Steel, Tokyo, (1970).

(8) S. Oketani, S. Hitomi and S. Nagakura : J. Japan Inst. Metals, 26 (1962), 494.

(9) H. Ino, T. Moriya, F. E. Fujita and Y. Maeda : J. Phys. Soc. Japan, 22 (1967), 346.

(10) K. H. Jack : J. Iron Steel Inst., 170 (1951), 248.

(11) A. J. Baker, P. M. Kelly and J. Nutting : Electron Microscopy and Strength of Crystals, Interscience, (1961), 899.

(12) M. J. Duggin and L. J. E. Hofer : Nature, 212 (1966), 248.

(13) M. J. Duggin : Trans. Met. Soc. AIME, 242 (1968), 1091.

(14) K. H. Jack and S. Wild : Nature, 212 (1966), 248.

(15) J. Crangle and W. Sucksmith : J. Iron Steel Inst., 168 (1951), 142. 


\section{Experimental Method}

\section{Materials}

The steels used in the present study are plain carbon steels containing $0.69 \% \mathrm{C}$ and $1.22 \% \mathrm{C}$ and their chemical compositions are shown in Table 1 . They were machined into the shape of rod with $3.8 \mathrm{~mm}$ diameter and $50 \mathrm{~mm}$ long for dilatometry, and into the shape of $1 \times 2 \times 50 \mathrm{~mm}^{3}$ for electrical resistivity measurements. For the thin foil preparation, the plate-like specimens of $1.5 \times 20 \times 20 \mathrm{~mm}^{3}$ were used.

Table 1 Chemical compositions of the steels used (wt \%)

\begin{tabular}{c|c|c|c|c|c} 
Steel & G & Si & Mn & P & S \\
\hline $0.69 \mathrm{C}$ & 0.69 & 0.28 & 0.67 & 0.019 & 0.012 \\
$1.22 \mathrm{C}$ & 1.22 & 0.26 & 0.60 & 0.002 & 0.007 \\
\hline
\end{tabular}

\section{Heat treatment}

After austenitizing in argon atmosphere for $5 \mathrm{~min}$ at $1200^{\circ} \mathrm{C}$, the specimens were quenched into iced brine in order to produce the mixed structure of martensite and retained austenite. Some of the $1.22 \% \mathrm{C}$ specimens were further quenched into liquid nitrogen for $117 \mathrm{hr}$ to reduce the retained austenite.

These quenched specimens were tempered at a constant heating rate of $5^{\circ} \mathrm{C} / \mathrm{min}$ in the furnace filled with helium gas using a SCR-PID type temperature controller. The electrical resistivity and the dilatometric measurements were carried out during this tempering and the specimens for electron microscopy were prepared by quenching into water from various temperatures during tempering.

\section{Electrical resistivity measurement}

The electrical resistivity and its temperature derivative were measured simultaneously during the tempering, and in order to eliminate the differences between the measurements, the electrical potential difference which was produced in the specimens was kept constant at $5 \mathrm{mV}$ by changing the current density.

\section{Dilatometry}

The dilatation during tempering was recorded optically by the Leitz HTV type dilatometer as a function of temperature with the magnification of about $\times 400$.

\section{Electron microscopy}

The specimens of various tempering stages were thinned down to $0.1 \mathrm{~mm}$ by polishing in a mixed solution of $\mathrm{H}_{2} \mathrm{O}_{2}, \mathrm{HF}$ and water ${ }^{(16)}$. The final electropolishing was carried out in the electrolyte of $\mathrm{H}_{3} \mathrm{PO}_{4}$ and $\mathrm{CrO}_{3}$. The thin foils were examined in a Hitachi HU-200 electron microscope operated at $200 \mathrm{kV}$.

\section{Experimental Results}

\section{Electrical resistivity measurement}

Figure 1 shows an example of the electrical resistivity

(16) F. Terasaki and A. Yoshikawa : Kinzoku Butsuri, 9(1963), 125. measurements during tempering of the $1.22 \% \mathrm{C}$ steel. It can be seen that the resistivity, its temperature derivative, and temperature itself were recorded simultaneously. The effects of carbon concentration and the sub-zero treatment on the temperature derivatives of the resistivity are shown in Fig. 2 and the reactions detected can be separated into at least three stages. Namely, the maximum decrease in the temperature derivatives of the resistivity can be seen at about $140^{\circ} \mathrm{C}$, but the others occurred at about $220^{\circ}$ and $280^{\circ} \mathrm{C}$ in both steels. The separations of these peaks which are shown by the broken lines were obtained by assuming the symmetry of the reactions against the temperature increase. Keeping in liquid nitrogen reduced the height of the reaction around $280^{\circ} \mathrm{C}$, but did not change the shape of this peak, i.e., its non-symmetric nature. Therefore, it seems likely that

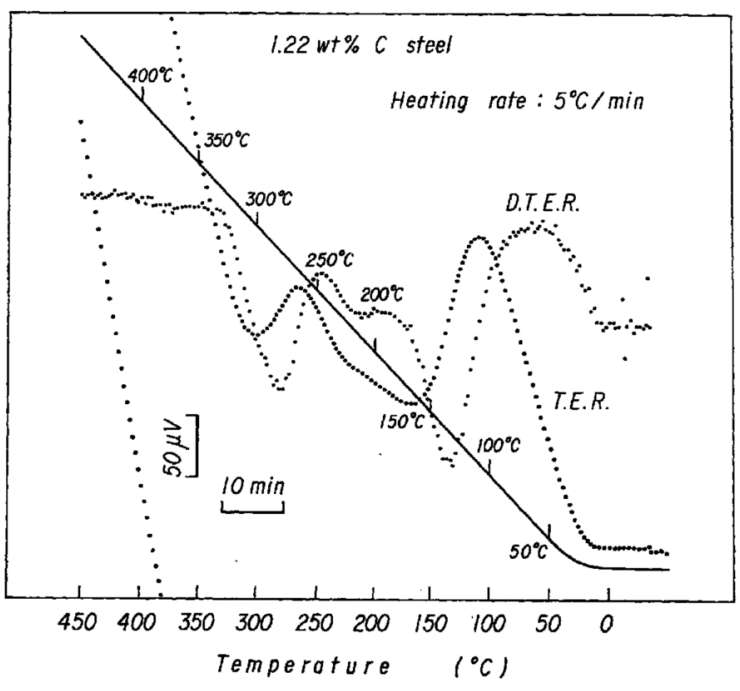

Fig. 1 An example of the electrical resistivity measurement during tempering of the $1.22 \% \mathrm{C}$ steel.

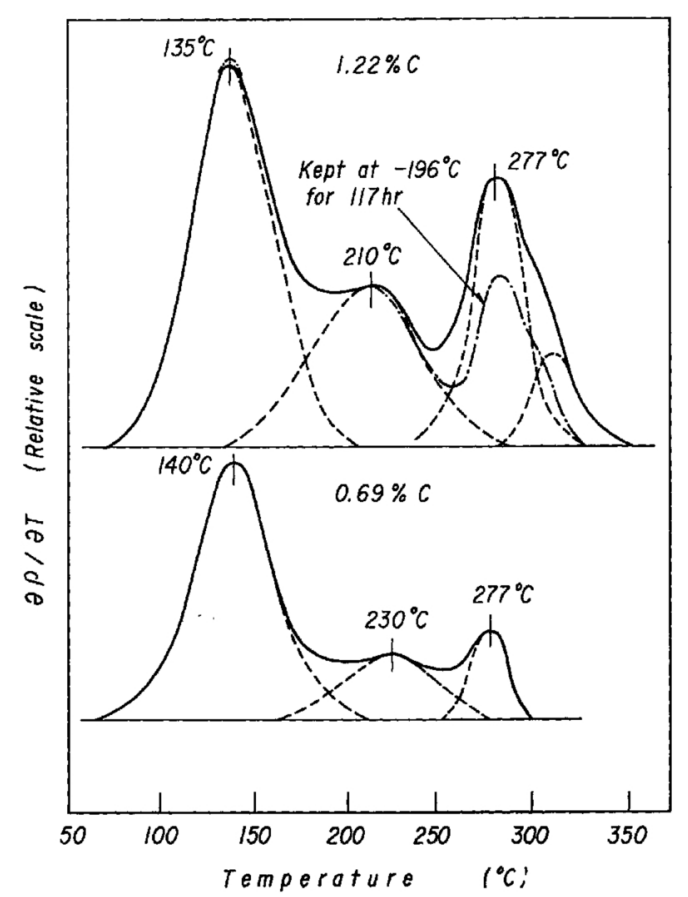

Fig. 2 The effects of carbon concentration and the sub-zero treatment on the temperature derivative of electrical resistivity. 
this corresponds to the decomposition of the retained austenite with two different stages.

\section{Dilatometry}

Figure 3 shows an example of the dilatometric measurements of the $1.22 \% \mathrm{C}$ martensite during tempering at $5^{\circ} \mathrm{C} / \mathrm{min}$, in which the variation of its length with temperature can be seen. The comparison of the temperature derivatives of these dilatation curves with those of the resistivities are shown in Fig. 4. Despite the exactly same tempering process, it can be seen that the temperature ranges of the reactions detected by dilatometry were not always identical with those by the resistivity measurements, suggesting that some of the reactions cannot be detected by either of them.

In the dilatometric measurements, the first reaction around $140^{\circ} \mathrm{C}$ was also observed as a large contraction, but the second one at $220^{\circ} \mathrm{C}$ did not exhibit any significant change in the length of the specimens. The third reaction in the resistivity measurements was detected as

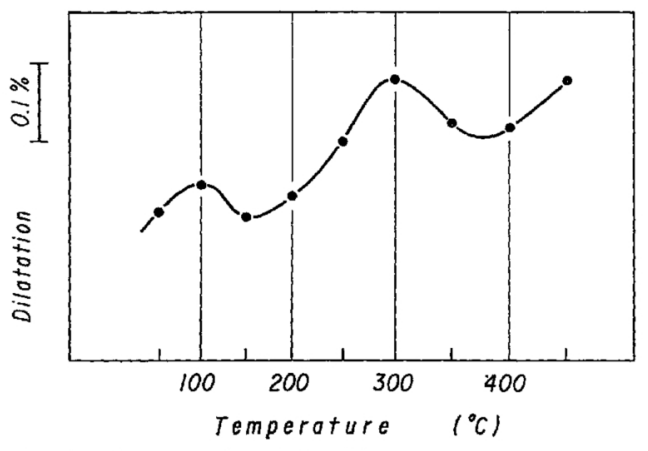

Fig. 3 An example of the dilatometric measurements during tempering of the $1.22 \% \mathrm{C}$ steel.

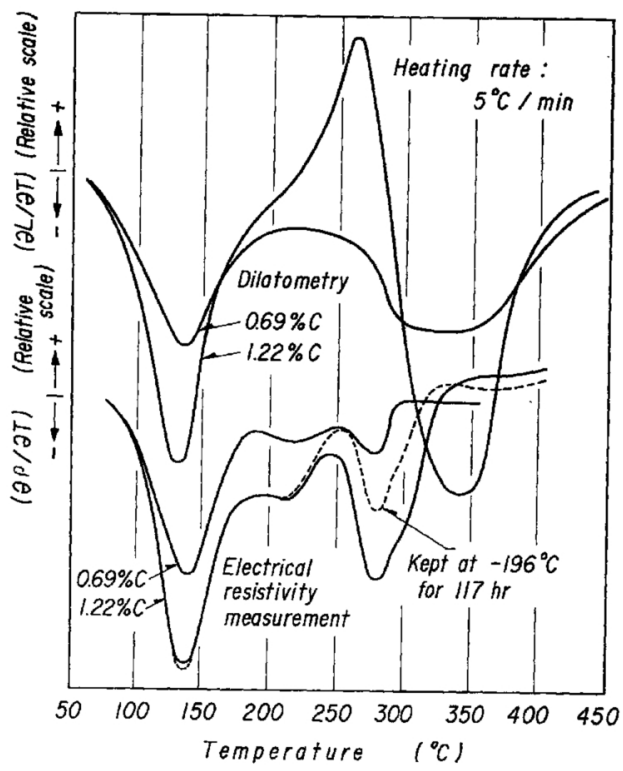

Fig. 4. The comparison of the temperature derivatives of the dilatation curves and those of the resistivities.

the expansion, but was overlapped by the reactions which occurred at a higher temperature with a large contraction.

\section{Electron microscopy}

Photo. 1 (a) shows the bright field image of the as-quenched $1.22 \% \mathrm{C}$ steel and it consists of martensite plates and the retained austenite between them. Photo. I (b) is the dark field image of the same area using the $(1 \overline{1} \overline{1})_{a}$ reflection which can be seen in the selected area electron diffraction pattern (Photo. 1 (c)). The scbematic representation of the diffraction pattern, Photo. I (d), indicates that the martensite is related to
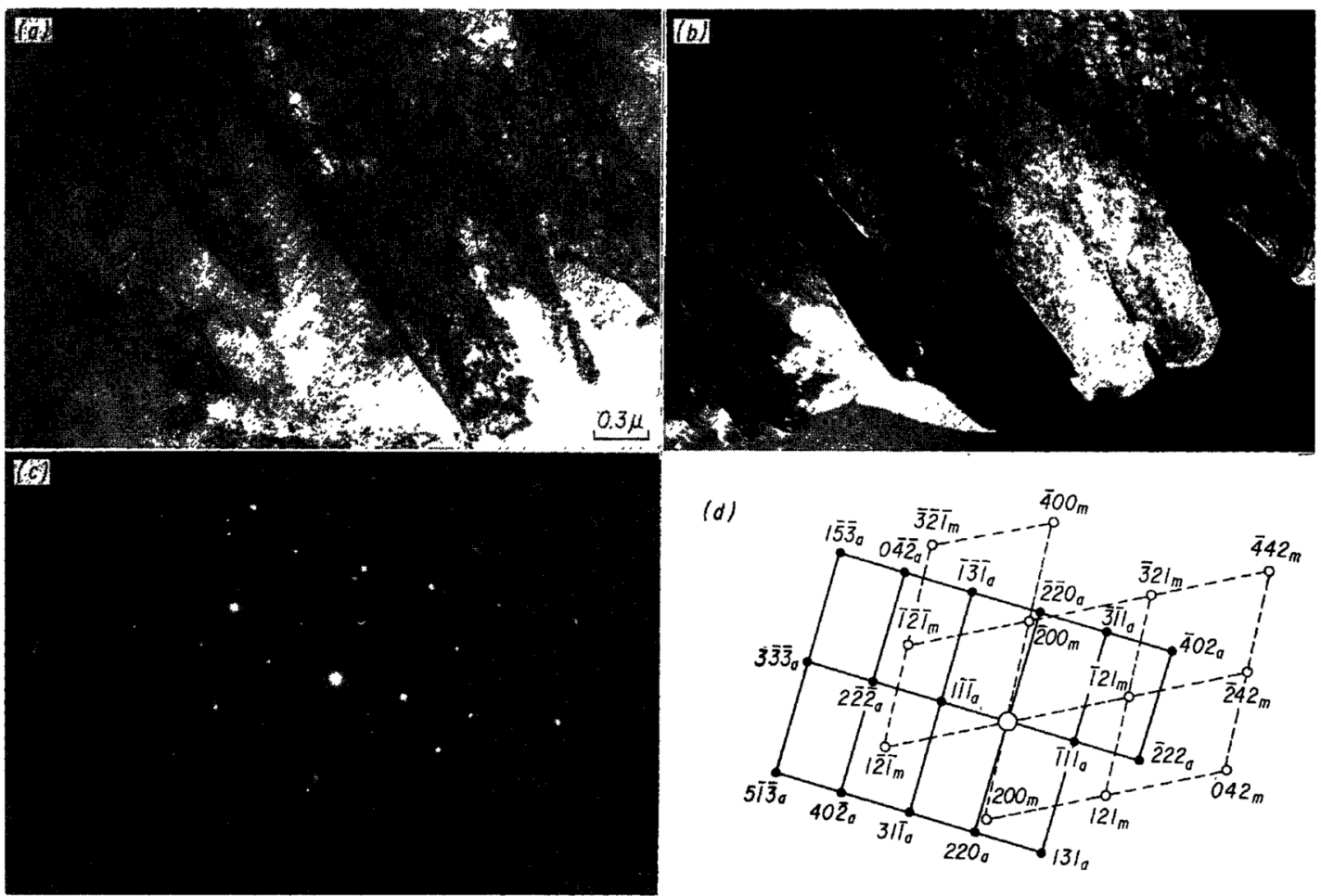

(d)

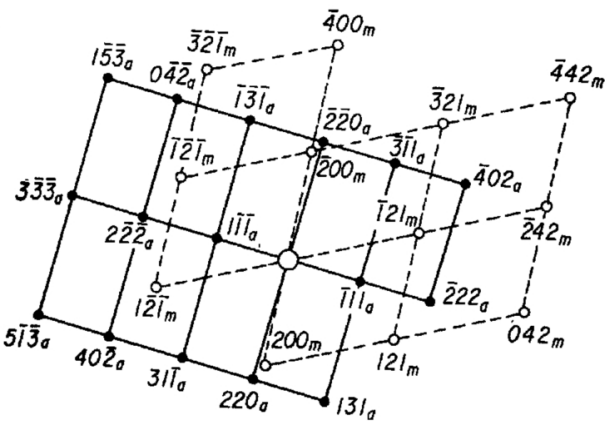

Photo. 1 As-quenched structure of the $1.22 \% \mathrm{C}$ steel.

(a) The bright field image, (b) the dark field image using the $(1 \overline{1} \overline{1})$ austenite reflection,

(c) the selected area electron diffraction pattern, and (d) its schematic representation. 
the parent austenite by the following Kurdjumow-Sachs orientation relationship ${ }^{(17)}$ :

$$
\begin{aligned}
& (0 \overline{1} 1)_{m} / /(1 \overline{1} 1)_{a}, \\
& (111)_{m} / /(011)_{a}, \\
& (\overline{2} 11)_{m} / /(\overline{2} 11)_{a} .
\end{aligned}
$$

Photos. 2 and 3 are the $0.69 \%$ and the $1.22 \% \mathrm{C}$ martensites tempered up to $150^{\circ} \mathrm{C}$, where the first reaction was almost completed. The bright field image of the $0.69 \% \mathrm{C}$ steel, the dark field image using the (110) twin reflection, the selected area electron diffraction pattern and its schematic representation are shown in Photos. 2 (a), (b), (c) and (d) respectively. In this micrograph, no significant differences from the as-
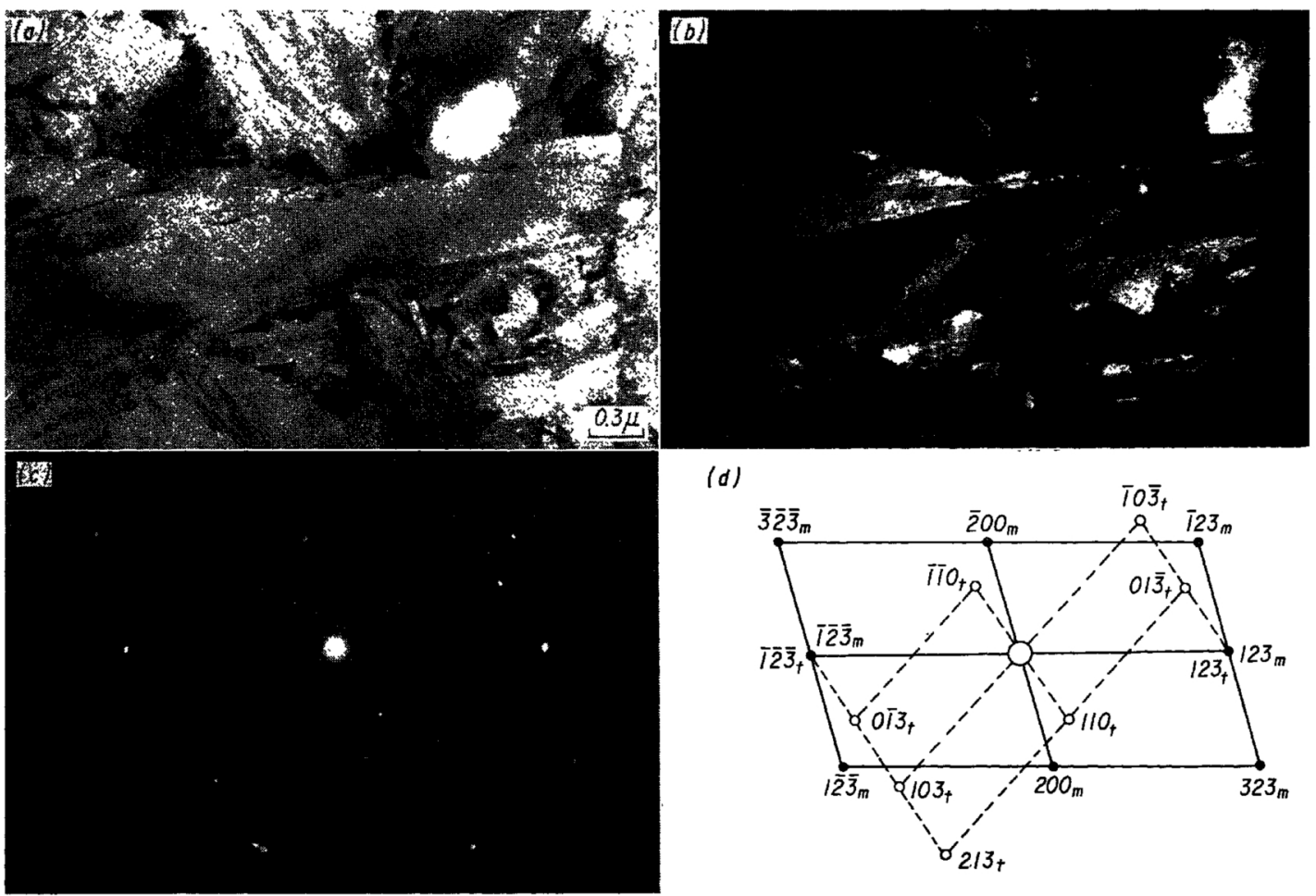

(d)

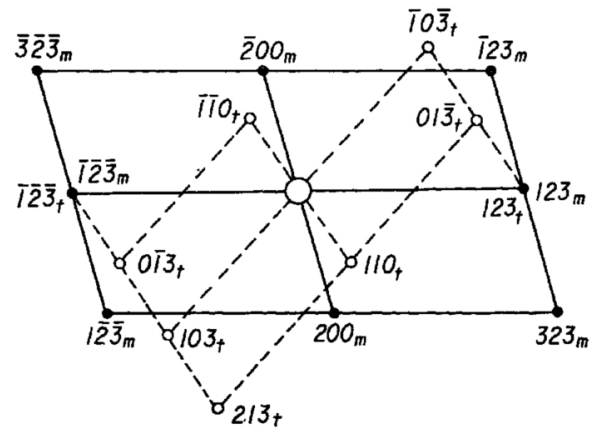

Photo. 2 The $0.69 \% \mathrm{C}$ martensite tempered up to $150^{\circ} \mathrm{C}$.

(a) The bright field image, (b) the dark field image using the (110) twin reflection,

(c) the selected area electron diffraction pattern and (d) its schematic representation.

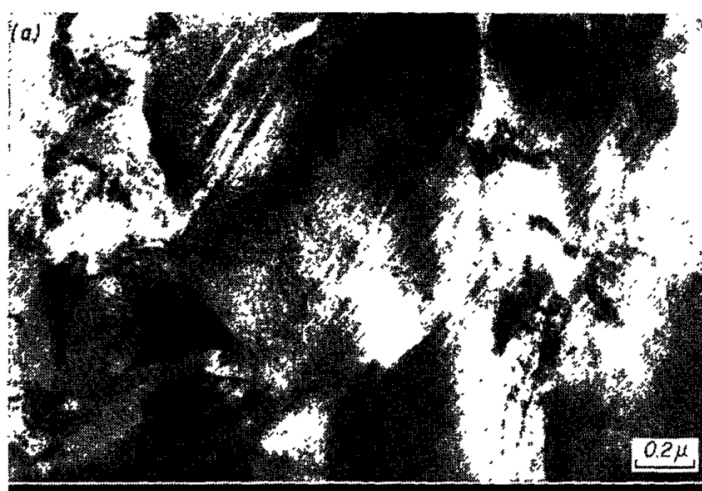

[b]

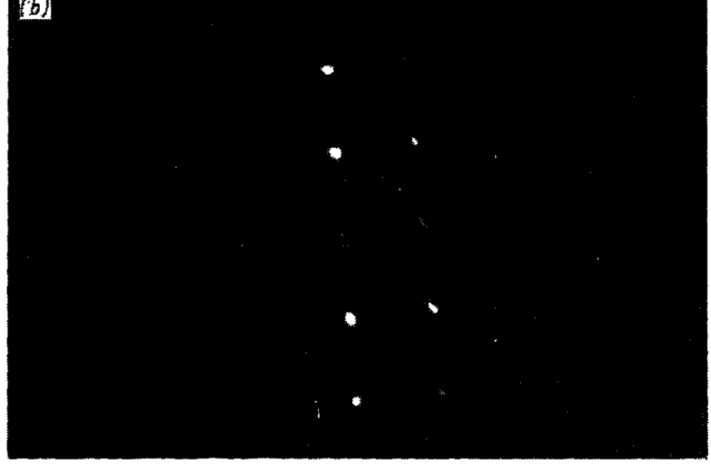

Photo. 3 The $1.22 \% \mathrm{C}$ martensite tempered up to $150^{\circ} \mathrm{C}$. (a) The bright field image and (b) its selected area electron diffraction pattern. quenched specimens can be observed. The transformation twin exhibited the following orientation relationship :

$$
\begin{aligned}
& (0 \overline{1} 1)_{m} / /(\overline{1} 10)_{t}, \\
& (111)_{m} / /(11 \overline{1})_{t}, \\
& (\overline{2} 11)_{m} / /(112)_{t} .
\end{aligned}
$$

When the $1.22 \% \mathrm{C}$ martensite was tempered up to 150 ${ }^{\circ} \mathrm{C}$, the second reaction has already started a little (Fig. 2). The microstructure of this specimen is shown in Photo. 3 (a) with its selected area electron diffraction pattern in (b). Although the reflections other than from the martensite matrix could not be detected, the bright field image was not exactly the same as those of the as-quenched one, but it appears that the precipitation of very fine particles has begun to occur slightly.

Tempering up to $230^{\circ} \mathrm{C}$, where the second reaction was observed clearly by the resistivity measurement, produced fine precipitates in the martensite, but the retained austenite with stacking faults in it showed no significant change as shown in Photo. 4. The bright field image of these particles in the $1.22 \% \mathrm{C}$ martensite matrix, its dark field image using a reflection from the precipitates, its selected area electron diffraction pattern, and the schematic representation of its analysis are shown

(17) G. V. Kurdjumow and G. Sachs : Z. Phys., 64 (1930), 325. 


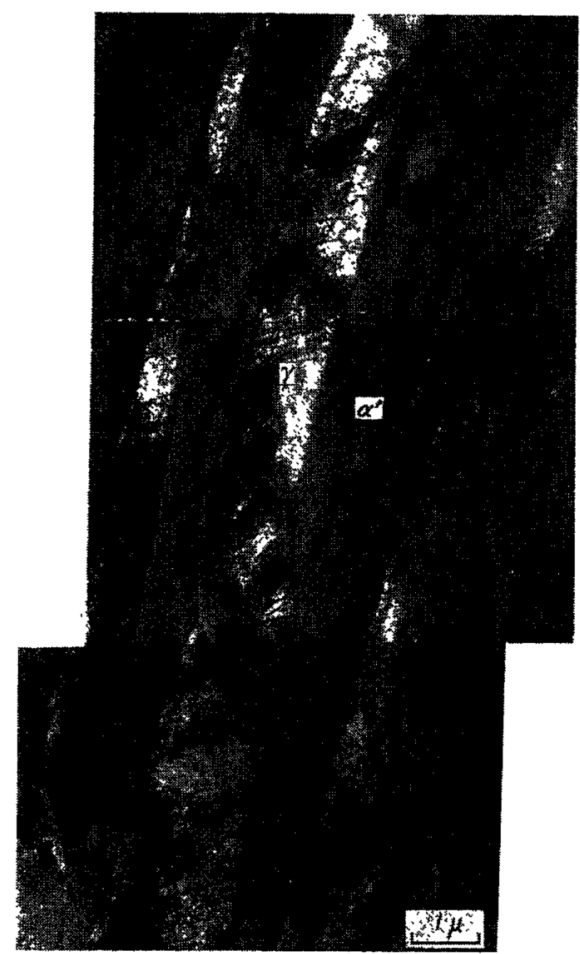

Photo. 4 The retained austenite in the $1.22 \%$.C steel tempered up to $230^{\circ} \mathrm{C}$. such $\varepsilon$-carbide/martensite orientation relationship are observed simultaneously and are given as

$$
\begin{array}{ll}
(0001)_{\varepsilon_{1}} / /(\overline{\mathrm{I}} 10)_{m} & (0001)_{\varepsilon_{2}} / /(\overline{\mathrm{I}} 01)_{m} \\
(0 \overline{\mathrm{I}} 10)_{\varepsilon_{1}} / /(\overline{\mathrm{I}} \mathrm{I} 2)_{m} & (\overline{\mathrm{I}} 100)_{\varepsilon_{2}} / /(121)_{m} .
\end{array}
$$

These orientation relationships are identical with that obtained by Jack(1), and very close to that by Hirotsu et al. ${ }^{(7)}$ between $\eta$-carbide and martensite, if the orthorhombic notation is employed.

On tempering up to $330^{\circ} \mathrm{C}$, the retained austenite was not observed at all, and in some areas a typical lower bainite in which cementite particles precipitated, Photos. 6 (a) and (b), was observed. However, in the untwinned areas of the martensite, $\varepsilon$-carbide continued to exist and showed distinct diffraction pattern as can be seen in Photos. 7 (a), (b), (c) and (d), and in Photos. 8 (a), (b) and (c). They exhibited the equivalent $\varepsilon$-carbide/ martensite orientation relationship described previously ${ }^{(1)}$. But in the twinned areas, $\chi$-carbide of the monoclinic $\mathrm{Pd}_{5} \mathrm{~B}_{2}$ type structure ${ }^{(12)(13)}$ was confirmed to precipitate by means of selected area electron diffraction. An example of $\chi$-carbide formation on the transformation twin interfaces, its dark field image using the $(\overline{2} 21)_{x}$ reflection, the selected area electron diffraction pattern, and its schematic rerepsentation are shown in
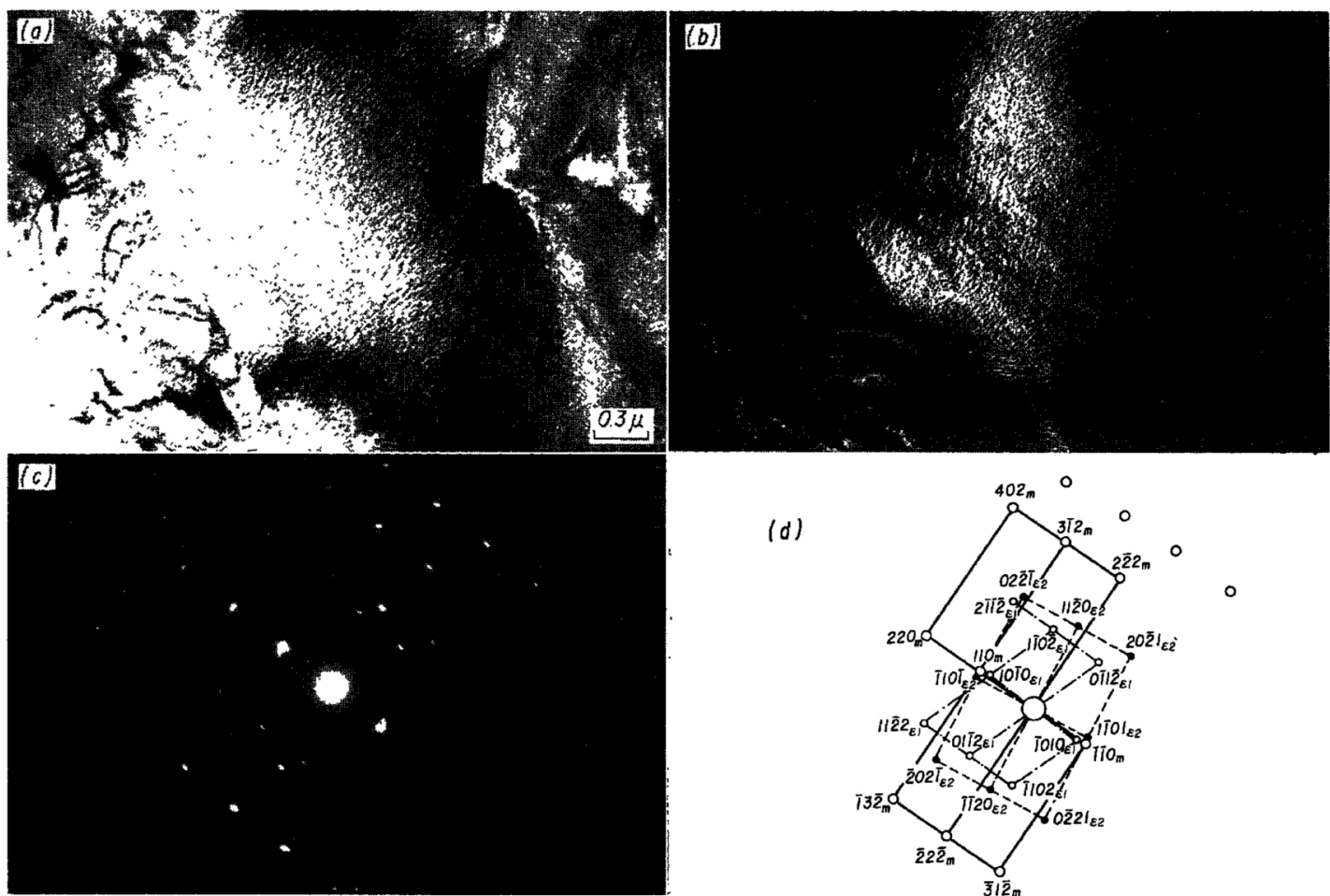

(d)

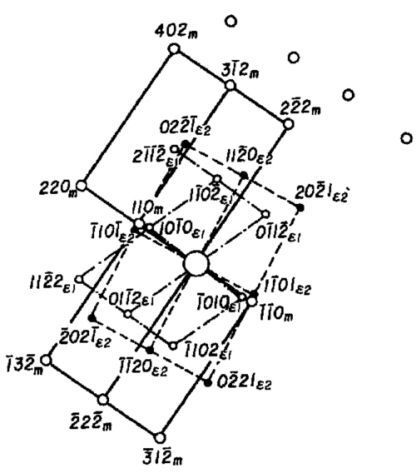

Photo. $5 \varepsilon$-carbide precipitation in the $1.22 \% \mathrm{C}$ martensite tempered up to $230^{\circ} \mathrm{C}$.

(a) The bright field image, (b) the dark field image using the (1102) $\varepsilon$-carbide reflection,

(c) the selected area electron diffraction pattern, and (d) its schematic representation.

in Photos. 5 (a), (b), (c) and (d) respectively. As the interplanar spacings and the angles between the reflections from these precipitates in the present study could be interpreted by assuming either the close packed hexagonal or the orthorhombic structure, the present results were analized in terms of the hexagonal $\varepsilon$-carbide determined by Jack ${ }^{(1)}$. In Photo. 5 (c), two variants of
Photos. 9 (a), (b), (c) and (d) respectively. This is the first direct evidence of $\chi$-carbide in the tempered martensite, and the $\chi$-carbide/ferrite orientation relationship can be determined from this diffraction pattern as :

$$
\begin{aligned}
& (100)_{x} / /(12 \overline{1})_{m}, \\
& (010)_{x} / /(\overline{1} 0 \overline{1})_{m}, \\
& {[001]_{z} / /[\overline{1} 11]_{m} .}
\end{aligned}
$$




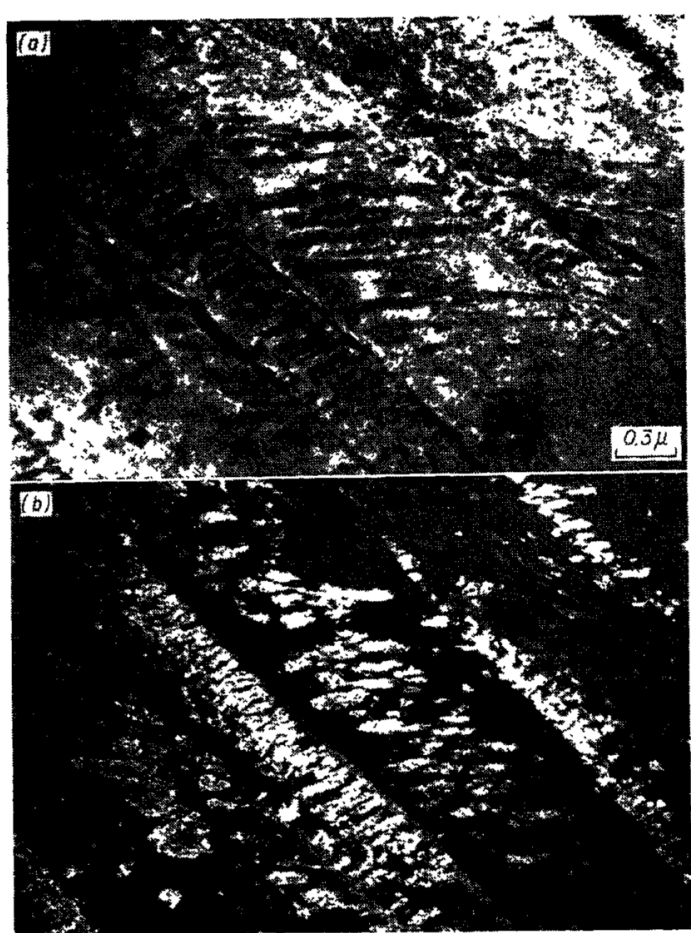

Photo. 6 The lower bainite formed in the $1.22 \% \mathrm{C}$ steel tempered up to $330^{\circ} \mathrm{C}$.

(a) The bright field image and (b) the dark field image using a cementite reflection. the Bagaryatskii cementite/ferrite orientation relationship $^{(18)}$ which is given as :

$$
\begin{aligned}
& (100)_{c} / /(10 \overline{1})_{m} / /(110)_{t}, \\
& (010)_{c} / /(\overline{1} \bar{I})_{m} / /(\overline{1} 11)_{t}, \\
& (001)_{c} / /(121)_{m} / /(1 \overline{1} 2)_{t} .
\end{aligned}
$$

While even at this temperature, $\chi$-carbide was still observed occasionally and there was no morphological difference between cementite and $\chi$-carbide precipitations.

\section{Discussion}

\section{The tempering stage}

The temperature range of each reaction is not so simple as it has been expected, and some of the reactions cannot be detected by both resistivity and dilatometric measurements. In order to distinguish the reactions observed, the results of the present study are summarized in Table 2 with their physical meanings.

It is interesting to note that the first reaction around $140^{\circ} \mathrm{C}$, which exhibited the decrease in the temperature derivative of the resistivity and of the dilatation does not seem to correspond to the $\varepsilon$-carbide formation.

The second reaction observed around $220^{\circ} \mathrm{C}$ is the $\varepsilon$ -

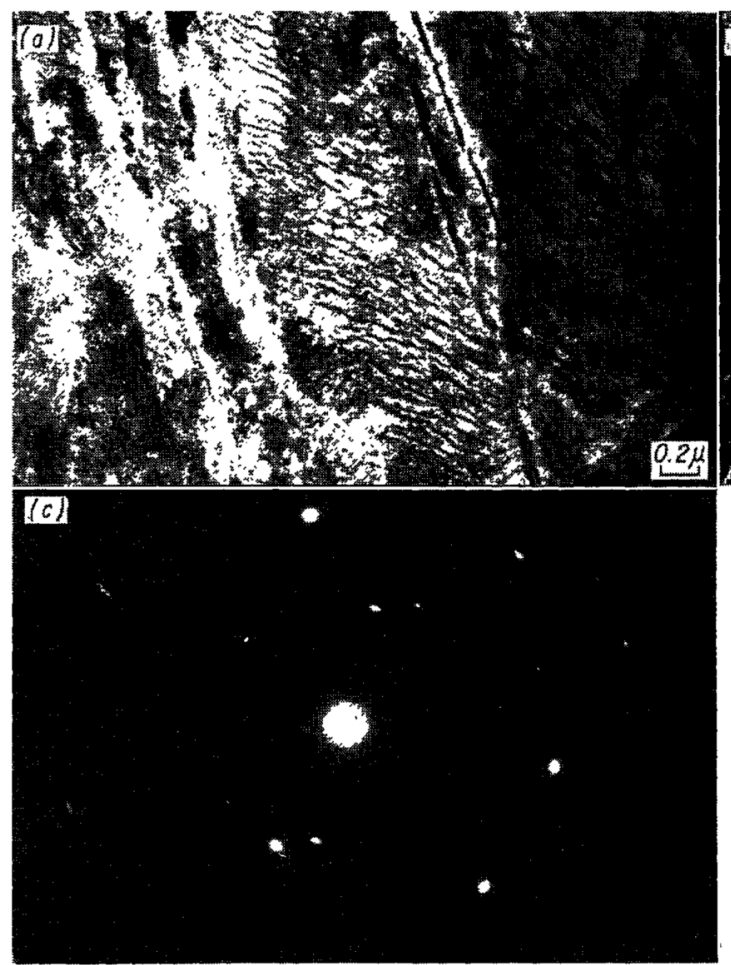

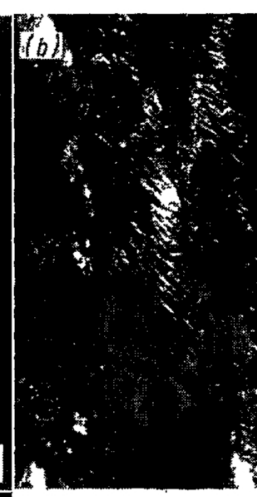

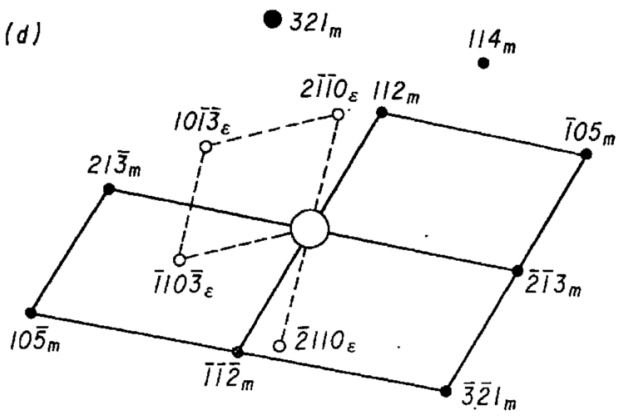

Photo. $7 \varepsilon$-carbide precipitation in the $1.22 \% \mathrm{C}$ martensite tempered up to $330^{\circ} \mathrm{C}$.

(a) The bright field image, (b) the dark field image using the $(\overline{2} 110)$-carbide reflection,

(c) the selected area electron diffraction pattern, and (d) its schematic representation.

Photo. 10 (a) shows the $\chi$-carbide formation on the twin interfaces at the mid-rib region and the dark field image using a $\chi$-carbide reflection confirmed it clearly (Photo. $10(\mathrm{~b}))$.

Further tempering up to $400^{\circ} \mathrm{C}$ transformed $\chi$-carbide into cementite on the twin interfaces as shown in Photos. 11 (a), (b), (c) and (d). This diffraction pattern exhibits carbide formation and it is quite difficult to attribute this to the decomposition of the retained austenite as suggested by the Moessbauer spectrum measurements $^{(9)}$.

In the temperature range between $230^{\circ}$ and $330^{\circ} \mathrm{C}$, three reactions were considered to be overlapping. They

(18) A. Bagaryatskii : Dokl. Akad. Nauk SSSR, 73 (1950), 1161. 

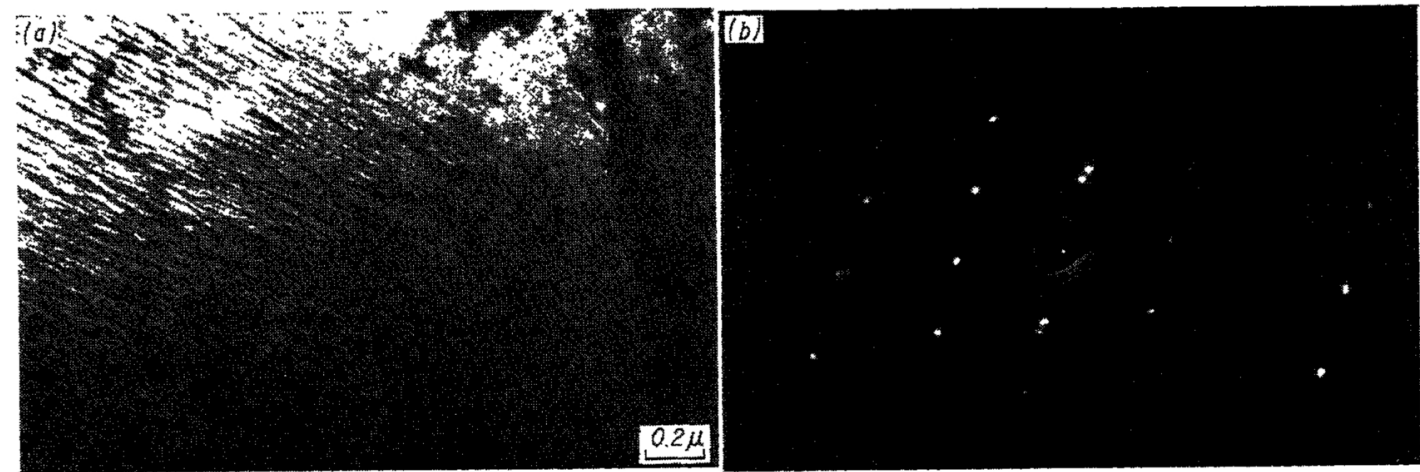

(c)

Photo. 8 The $\varepsilon$-carbide precipitation in the untwinned region of the $1.22 \% \mathrm{C}$ martensite tempered up to $330^{\circ} \mathrm{C}$. (a) The bright field image, (b) the selected area electron diffraction pattern, and (c) its schematic representation.
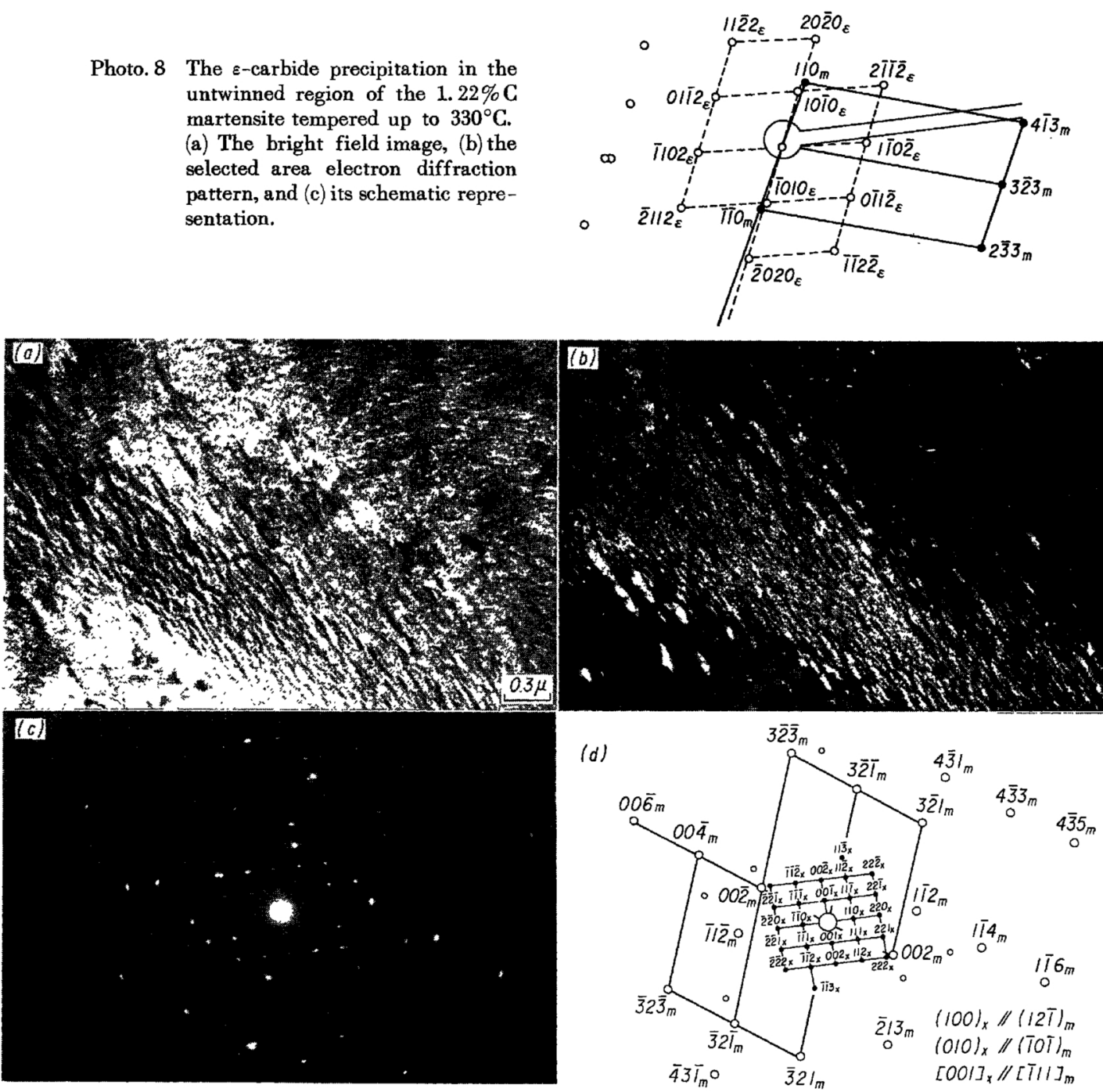

Photo. 9 The $\chi$-carbide formation on the twin interfaces in the $1.22 \% \mathrm{C}$ martensite tempered up to $330^{\circ} \mathrm{C}$ (a) The bright field image, (b) the dark field image using the (221) $\chi$-carbide reflection, (c) the selected area electron diffraction pattern, and (d) its schematic representation.

were two different processes of the retained austenite decomposition (which was concluded from the nonsymmetric shape of the temperature derivative of the resistivity) and the precipitation of $\chi$-carbide on the twin interfaces.

The last stage of tempering is the in situ transformation of $\chi$-carbide into cementite at temperatures above $350^{\circ} \mathrm{C}$.

\section{The tempering process prior to the} $\varepsilon$-carbide formation
The decrease of the electrical resistivity around $140^{\circ} \mathrm{C}$ does not appear to arise from the $\varepsilon$-carbide formation but may correspond to the pre-precipitation stage such as the segregation of carbon atoms to the lattice defects ${ }^{(19)}$ or the formation of the carbon clusters ${ }^{(20)}$. The segregation of earbon atoms to the dislocation lines in low carbon martensite was suggested by Speich ${ }^{(19)}$ from the

(19) G. R. Speich : Trans. Met. Soc. AIME, 245 (1960), 2553.

(20) Z. Nishiyama : Symposium on Martensite Transformation in honor of Prof. Z. Nishiyama on the occasion of his retirement from Osaka University, Osaka, (1965). 


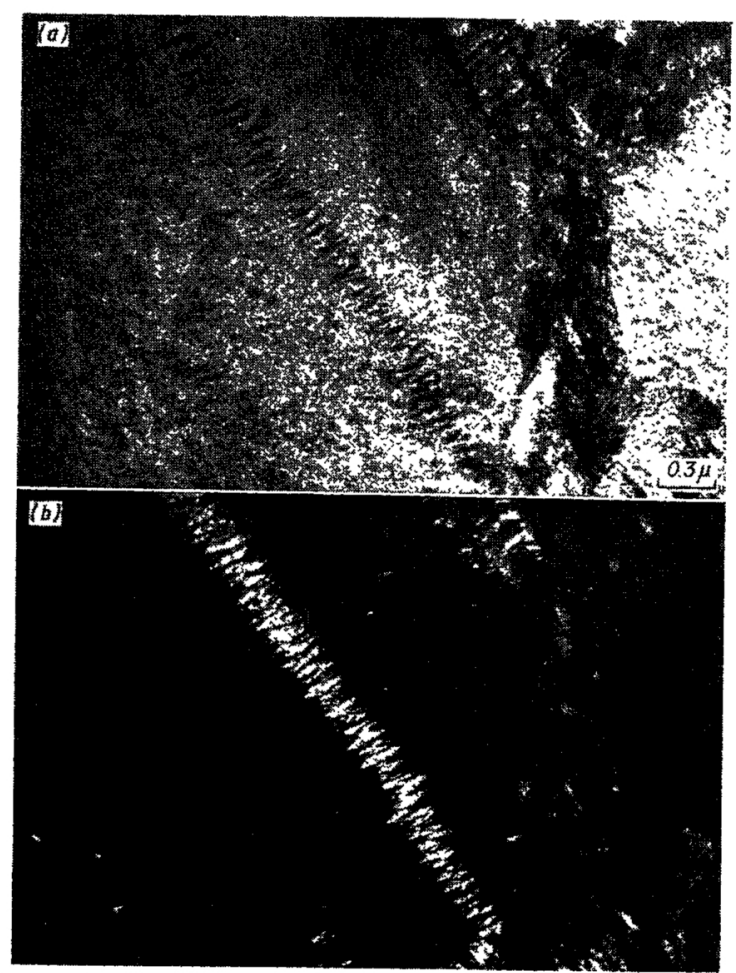

Photo. 10 The $\chi_{\text {-carbide formation on the twin interfaces at }}$ the midrib region of the $1.22 \% \mathrm{C}$ martensite tempered up to $330^{\circ} \mathrm{C}$.

(a) The bright field image, and (b) the dark field image using a $\chi_{\text {-carbide reflection. }}$
${ }^{\circ} \mathrm{C}^{(21)(22)}$, and that a similar phenomenon occurred by tempering even at temperatures as low as $59^{\circ} \mathrm{C}^{(20)}$. Since the diffraction patterns from the $\varepsilon$-carbide could not be obtained in these specimens, he suggested this might be due to the carbon cluster formation which preceded the $\varepsilon$-carbide formation ${ }^{(20)}$. It is also note worthy that the electron configulation at this tempering stage was confirmed to be almost similar to that in the virgin martensite by Moessbauer spectrum measurements ${ }^{(9)}$. This appears to support the existence of the pre-precipitation stage prior to the $\varepsilon$-carbide formation, in good agreement with the present results.

\section{The precipitation of $\varepsilon$-carbide}

As pointed out above, the only difference between the present results and the previous data exists in the temperature range of the $\varepsilon$-carbide formation; i.e., the $\varepsilon$ carbide formation produced the second decrease in the temperature derivative of the resistivity instead of the first one. It is interesting to note that the $\varepsilon$-carbide formation was not detected by means of dilatometry. If the $\varepsilon$-carbide is assumed to precipitate in ferrite, the ferrite lattice which transforms into $\varepsilon$-carbide lattice has to expand about $18 \%$ in volume ${ }^{(3)}$. Therefore, this is probably cancelled out by the contraction due to the reduced tetragonality of the martensite, exhibiting no dilatometric change.
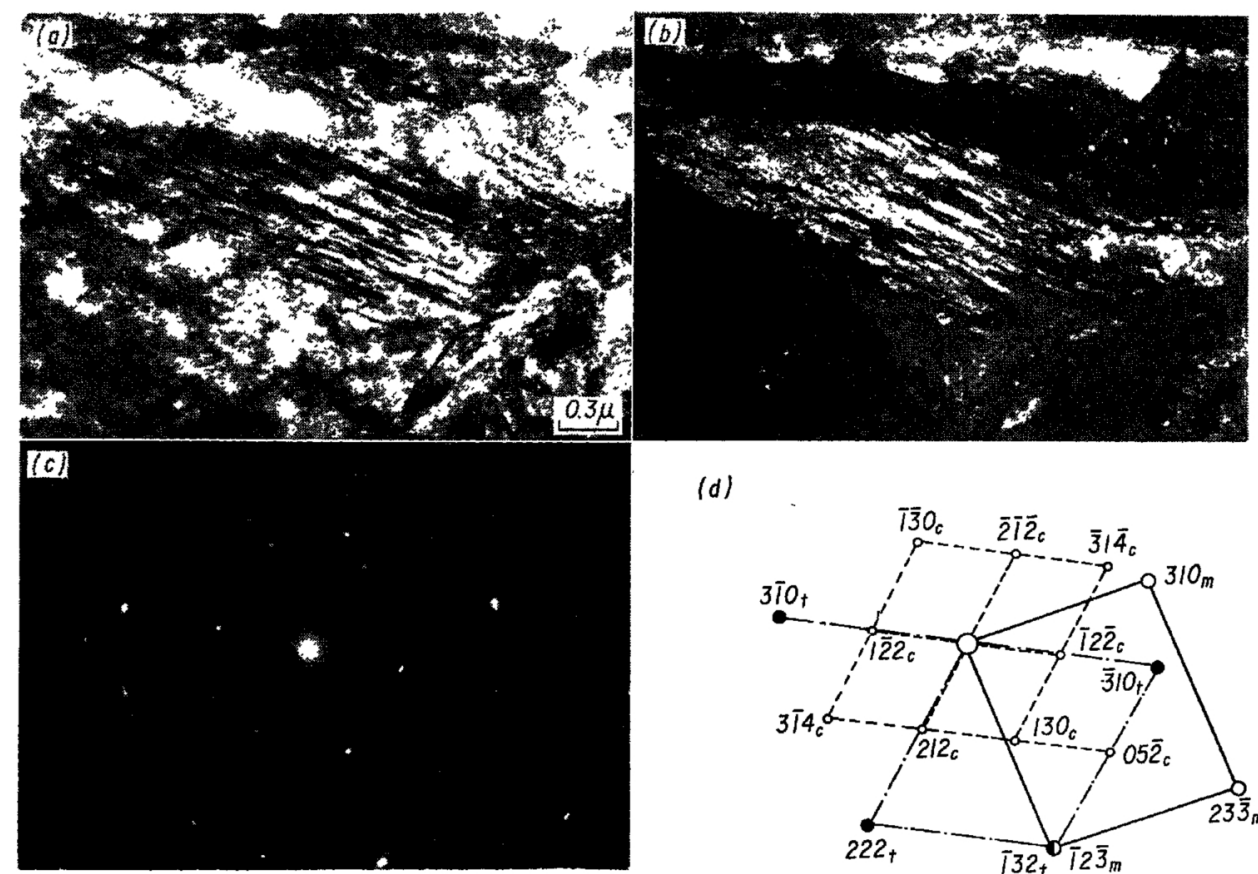

(d)

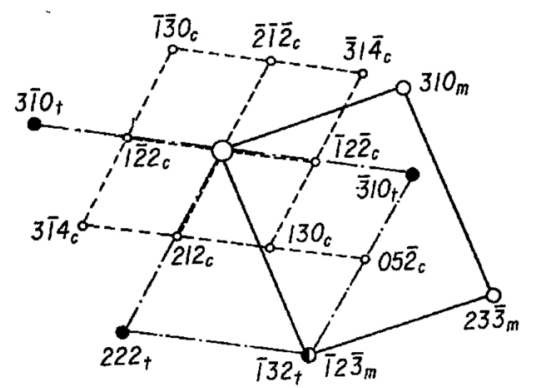

Photo. 11 The cementite formation on the twin interfaces in the $1.22 \% \mathrm{C}$ martensite tempered up to $400^{\circ} \mathrm{C}$. (a) The bright field image, (b) the dark field image using the (12) 2 -cementite reflection, (c) the selected area electron diffraction pattern, and (d) its schematic representation.

results of the resistivity measurements but he attributed the same reaction in higher carbon steels to the $\varepsilon$-carbide formation. However, this discontinuous assumption from low to high carbon steels is rather questionable, and it is more likely that the same reaction occurred at this temperature. Nishiyama also found that the martensite lost its tetragonality by tempering at 150

\section{The decomposition of the retained austenite}

The decomposition of the retained austenite occurred in the temperature range between $230^{\circ} \mathrm{C}$ and $330^{\circ} \mathrm{C}$,

(21) Z. Nishiyama : J. Japan Inst. Metals, 4 (1940), 109.

(22) Z. Nishiyama : J. Japan Inst. Metals, $8(1944), 423$. 
Table 2 Tempering stages and their interpretations

\begin{tabular}{|c|c|c|c|c|}
\hline Temperature & R. T. $\longleftrightarrow 150^{\circ} \mathrm{C}$ & $130^{\circ} \mathrm{C} \longleftrightarrow 250^{\circ} \mathrm{C}$ & $230^{\circ} \mathrm{C} \longleftrightarrow 330^{\circ} \mathrm{C}$ & $330^{\circ} \mathrm{C} \longleftrightarrow 400^{\circ} \mathrm{C}$ \\
\hline $\begin{array}{l}\text { Electrical } \\
\text { resistivity }\end{array}$ & Decrease & Decrease & Decrease & - \\
\hline Dilatometry & Contraction & - & Expansion & Contraction \\
\hline Electron microscopy & $\begin{array}{l}\text { (1) Martensite } \\
\text { (2) Retained austenite }\end{array}$ & $\begin{array}{l}\text { (1) Tempered martensite } \\
\text { ( } \varepsilon \text {-carbide) } \\
\text { (2) Retained austenite }\end{array}$ & $\begin{array}{l}\text { (1) Tempered martensite } \\
\left(\begin{array}{l}\varepsilon \text {-carbide in the } \\
\text { matrix } \\
\chi \text {-carbide on the } \\
\text { twin interfaces }\end{array}\right) \\
\text { (2) Lower bainite }\end{array}$ & $\begin{array}{l}\text { Tempered martensite } \\
\left(\begin{array}{l}\text { cementite and } \\
\chi \text {-carbide on the } \\
\text { twin interfaces }\end{array}\right)\end{array}$ \\
\hline Interpretation & $\begin{array}{l}\text { Segregation of carbon } \\
\text { a toms to the lattice } \\
\text { defects or the carbon } \\
\text { cluster formation }\end{array}$ & $\begin{array}{l}\text { Precipitation of } \\
\varepsilon \text {-carbide }\end{array}$ & $\begin{array}{l}\text { Precipitation of } \chi_{-} \\
\text {carbide on the twin } \\
\text { interfaces and the } \\
\text { decomposition of } \\
\text { retained austenite }\end{array}$ & $\begin{array}{l}\text { Transition of } \chi \text {-carbide } \\
\text { into cementite }\end{array}$ \\
\hline
\end{tabular}

and the lower bainite transformation was observed as reported previously ${ }^{(23)}$. The lower bainite in plain carbon steels usually consists of the ferrite plates involving fine cemcntite platelets ${ }^{(24) \sim(26)}$, while the temperature derivative of the resistivity showed a non-symmetric shape, indicating the existence of the two stages in its decomposition. Although there is no direct evidence, the one is probably the bainite containing $\varepsilon$-carbide and the other is a normal lower bainite.

\section{The precipitation of $\chi_{\text {-carbide }}$}

The precipitation of $\chi$-carbide was first confirmed in the present study directly, and this is consistent with the result of magnetic measurements ${ }^{(15)}$. However, it should be noted that the $\chi$-carbide formed only on the transformation twin interfaces. This is probably the reason why by means of electron microscopy $\chi$-carbide has not been observed in low carbon steels where the lattice invariant shear is in the form of slip. Although Tekin and $\mathrm{Kelly}^{(3)}$ pointed out that the twin interfaces produced much wider sites for carbon atoms than the matrix, $\varepsilon$-carbide did not precipitate on them. Therefore, the structural similarity between $\chi$-carbide and the twin interfaces must be considered. One of the authors (Y. O.) has already shown that the crystallographic structure of the twin interface is much closer to the cementite structure than that of the matrix and that the (101) cementite plane is almost similar to the $\{112\}$ twin plane ${ }^{(26)}$, which explains the orientation relationship between the twinned martensite and cementite. The close structural similarity between $\chi$ carbide and cementite proposed by Duggin ${ }^{(13)}$ as well as the cementite/twinned ferrite relationship described above suggests the possibility of the twin interface precipitation of $\chi$-carbide. In effect the orientation relationship between ferrite and $\chi$-carbide is consistent with both the cementite/ $\chi$-carbide orientation relationship suggested by Duggin ${ }^{(13)}$ and the cementite/twinned ferrite relationship ${ }^{(26)}$.

(23) T. Ko : Acta Met., 2(1954), 75.

(24) K. Shimizu, T. Ko and Z. Nishiyama : J. Japan Inst. Metals, 27 (1963), 506.

(25) G. R. Srinivasan and C. M. Wayman : Acta Met., 16(1968), 607 .

(26) Y. Ohmori : Ph. D. Thesis, Univ. Cambridge, (1969).

\section{The precipitation of cementite}

Since no morphological difference between cementite and $\chi$-carbide formation was observed and their close structural similarity has been reported ${ }^{(13)}$, it seems likely that the $\chi$-carbide on the twin interfaces transforms into cementite in an in situ fashion.

Whereas in the present study it cannot be discussed in which manner the $\varepsilon$-carbide particles in the untwinned region transforms to cementite.

\section{Conclusions}

The tempering process of plain carbon martensite was investigated by means of dilatometry, electrical resistivity measurements and transmission electron microscopy, and the following results were obtained :

(1) The first stage of tempering which produces a large contraction in length and a decrease of the temperature derivative of resistivity does not correspond to the $\varepsilon$-carbide formation but is assumed to be the segregation of carbon atoms to the lattice defects or the formation of carbon clusters.

(2) The $\varepsilon$-carbide precipitation occurs in the temperature range between $150^{\circ}$ and $250^{\circ} \mathrm{C}$ accompanying a slight decrease in electrical resistivity.

(3) The retained austenite decomposes into lower bainite in the temperature range between $230^{\circ}$ and 330 ${ }^{\circ} \mathrm{C}$.

(4) Tempering up to $330^{\circ} \mathrm{C}$ produces the $\chi$-carbide on the transformation twin interfaces but $\varepsilon$-carbide is still observed in the martensite matrix.

(5) The $\chi$-carbide on the twin interfaces transforms into cementite in an in situ manner at temperatures above $350^{\circ} \mathrm{C}$.

\section{Acknowledgments}

Our sincere thanks are due to Dr. M. Sumitomo, managing director of Sumitomo Metal Industries, for the permission to publish the present results. We are also grateful to Emeritus Prof. M. Okada and Dr. T. Kunitake for their helpful advices and stimulating discussions. Thanks are also due to Dr. T. Shiraiwa and Dr. F. Terasaki for providing the facilities of electron microscopy. 